\title{
Micafungin induced apoptosis in Candida parapsilosis independent of its susceptibility to micafungin
}

\author{
Fazal Shirazi ${ }^{1}$, Russel E. Lewis ${ }^{1,2}$, Dimitrios P. Kontoyiannis ${ }^{1, *}$ \\ ${ }^{1}$ Department of Infectious Diseases, Infection Control and Employee Health, The University of Texas M D Anderson Cancer Center, \\ Houston, TX, USA. \\ ${ }^{2}$ Current Address: Department of Medical and Surgical Sciences, University of Bologna, Bologna, Italy. \\ * Corresponding Author: Dimitrios P. Kontoyiannis, MD, ScD, Department of Infectious Diseases, Infection Control and Employee \\ Health, The University of Texas MD Anderson Cancer Center, 1515 Holcombe Boulevard; Houston, TX 77030, USA; Tel: +1 713792 \\ 6237; Fax: +1 713745 6839; E-mail: dkontoyi@mdanderson.org
}

\begin{abstract}
We hypothesized that the cell wall inhibitor micafungin (MICA) induces apoptosis in both MICA-susceptible (MICA-S) and MICA-nonsusceptible (MICA-NS) Candida parapsilosis. Antifungal activity and apoptosis were analyzed in MICA-S and MICA-NS C. parapsilosis strains following exposure to micafungin for $3 \mathrm{~h}$ at $37^{\circ} \mathrm{C}$ in RPMI 1640 medium. Apoptosis was characterized by detecting phosphatidylserine externalization (PS), plasma membrane integrity, reactive oxygen species (ROS) generation, mitochondrial membrane potential changes, adenosine triphosphate (ATP) release, and caspase-like activity. Apoptosis was detected in MICA exposed (0.25 to 1 $\mathrm{mg} / \mathrm{L}$ ) susceptible $C$. parapsilosis strains and was associated with apoptosis of $\mathbf{2 0 - 5 2 \%}$ of analyzed cells versus only $5-30 \%$ of apoptosis in MICA-NS cells exposed to micafungin $(0.5$ to $2 \mathrm{mg} / \mathrm{L} ; \mathrm{P}=0.001)$. The MICA antifungal activity was correlated with apoptotic cells showing increased dihydrorhodamine-123 staining (indicating ROS production), Rh-123 staining (decreased mitochondrial membrane potential), elevated ATP, and increased metacaspase activity. In conclusion, MICA is pro-apoptotic in MICA-S cells, but still exerts apoptotic effects in MICA -NS C. parapsilosis.
\end{abstract}

doi: $10.15698 /$ mic2015.11.236 Received originally: 28.05 .2015 ; in revised form: 15.09.2015, Accepted 24.09.2015, Published 23.10.2015.

Keywords: apoptosis, micafungin, metacaspase, reactive oxygen species.

\author{
Abbreviations: \\ MIC - minimum inhibitory \\ concentration, \\ MICA - micafungin, \\ MICA-NS - MICA-non-susceptible, \\ MICA-S - MICA-susceptible, \\ $P S$ - phosphatidylserine, \\ $R O S$ - reactive oxygen species.
}

\section{INTRODUCTION}

Candida parapsilosis is a common cause of invasive candidiasis, especially in the setting of catheter associated blood stream infection [1-3]. The ability of Candida spp. to form biofilms on catheters has made candidiasis difficult to treat due to increased resistance to antifungal agents [4]. Echinocandins play a significant role in the treatment of invasive candidiasis [5]. These agents are non-toxic and exert potent fungicidal activity against Candida spp. through the inhibition of (1,3)- $\beta-D$ glucan synthesis, a major constituent of the fungal cell wall [6]. In addition, they are the most promising antifungal agents for lock therapy strategies [4]. Although the effects of echinocandin activity have been extensively investigated by standard microbiological endpoints, an improved understanding of the mechanistic basis of micafungin (MICA)-induced cell death in Candida may provide new insights into effective antifungal strategies, especially in the era of increasing echinocandin resistance in Candida species.
A series of morphologic and biochemical features like exposure of phosphatidylserine (PS), DNA fragmentation, reactive oxygen species (ROS) accumulation and mitochondrial depolarization set apoptosis apart from necrosis [1]. Apoptotic responses have been studied in many higher eukaryotes but also have been observed in lower eukaryotes, including yeasts and filamentous fungi [7-10]. As other lower eukaryotes, Candida spp. exhibit apoptotic markers that are similar to mammalian cells, including externalization of phosphatidylserine, reactive oxygen species (ROS) accumulation, decreased mitochondrial membrane potential, and DNA condensation and fragmentation $[3,11]$. Furthermore, apoptosis can be induced in C. albicans by oxidative stress, intracellular acidification and antifungal agents such as amphotericin B and caspofungin [1, 12-15]. However, it is unclear whether apoptotic effects in Candida are related to the degree of echinocandin susceptibility. Therefore, we hypothesized that the echinocandin MICA, although more pro-apoptotic in micafungin-susceptible (MI- 
CA-S) C. parapsilosis cells, would also induce apoptosis in micafungin -non-susceptible (MICA-NS) C. parapsilosis cells.

\section{RESULTS}

Micafungin induces more pronounced apoptosis in MICAsusceptible $C$. parapsilosis planktonic cells versus a nonsusceptible strain

The MICA concentrations used for apoptotic studies were based on the susceptibility of the two $C$. parapsilosis isolates to MICA, minimum inhibitory concentration (MIC) for MICA-S strain being $1 \mathrm{mg} / \mathrm{L}$ and for MICA-NS $2 \mathrm{mg} / \mathrm{L}$. To assess whether MICA activity occurs through induction of apoptosis, we exposed $C$. parapsilosis planktonic cells to MICA concentration at MIC or sub-MIC level, as it was reported that concentration at MIC or above MIC leads to necrosis, hence annexin- $\mathrm{V}$ and propidium iodide (PI) staining were performed following exposure to different concentrations of MICA. For the MICA-S C. parapsilosis strain, up to $52 \%$ of planktonic cells exposed to micafungin (Table 1) showed apoptosis, whereas for the MICA-NS C. parapsilosis strain, only $30 \%$ of MICA - treated planktonic cells were apoptotic $(P=0.001)$ (Table 1$)$.

ROS play an important role as an early initiator of apoptosis in yeasts and other filamentous fungi. MICA-S C. parapsilosis planktonic cells exhibited a 2.4 - fold increase in ROS levels compared to untreated cells following MICA exposure. In contrast, a 1.5 fold increase in fluorescence in the MICA-NS C. parapsilosis planktonic cell exposed to MICA versus untreated cells $(P=0.006)$ (Table 1 , Fig. $1 A)$. Similarly, MICA exposure was associated with decreases in mitochondrial membrane potential in both MICA-S and MICA-NS strains of $C$. parapsilosis (3.8 fold vs 2.0 fold increase in fluorescence, $\mathrm{P}=0.0025$, Table 1 ).

Micafungin damages the cell membrane of $C$. parapsilosis planktonic cells, especially in MICA-S strains

A rapid efflux of ATP due to membrane damage by MICA was detected after the incubation of $C$. parapsilosis planktonic cells with MICA for $3 \mathrm{~h}$ at $37^{\circ} \mathrm{C}$ (Fig. $1 \mathrm{~B}$ ). Specifically, we observed higher degree of ATP release among MICA-S C. parapsilosis strain following MICA exposure $(0.5-1 \mathrm{mg} / \mathrm{L})$ as compared to MICA-NS strain (Fig. 1B). This increased ATP release was consistent with increased ROS generation and decreased mitochondrial membrane potential of cells incubated with MICA.

Micafungin activates metacaspases (caspase-like activity) in C. parapsilosis planktonic cells, especially in MICA-S strains

Researchers have identified orthologs of mammalian caspases called metacaspases in yeast and filamentous fungi, which are activated in the early stages of apoptosis $[8,15]$. In fungi and plants, metacaspases (caspase-like) activity can be assessed using the in situ detection marker CaspACE FITC-VAD-FMK $[9,10]$. To confirm the presence of metacaspase activation, MICA - pretreated $(0.5-1 \mathrm{mg} / \mathrm{L}) \mathrm{C}$. parapsilosis planktonic cells were incubated with CaspACE FITC-VAD-FMK, which fluoresces green when it binds to active metacaspases. Indeed, the planktonic cells of MICA$\mathrm{S}$ and MICA-NS C. parapsilosis treated with MICA showed green fluorescence, suggesting that apoptosis in these cells occurs via metacaspase activation irrespective of MICA susceptibility (Figure $1 \mathrm{C}, \mathrm{D}$ ).

To further support the concept that caspase-like activity are involved in apoptosis, we treated $C$. parapsilosis planktonic cells with 0.5 to $1.0 \mathrm{mg} / \mathrm{L}$ MICA for $3 \mathrm{~h}$ in the presence or absence of the caspase 1 inhibitor Z-VAD-FMK at a concentration of $40 \mu \mathrm{M}$. MICA treated cells were assessed for the metacaspase activity in Z-VAD-FMK - treated and untreated samples of the $C$. parapsilosis planktonic cells. C. parapsilosis susceptible planktonic cells treated with MICA in combination with Z-VAD-FMK exhibited less fluorescence in cells ( 3.38 fold), than did cells treated with only MICA (13.74 fold). Similarly, C. parapsilosis nonsusceptible cells showed decrease in fluorescence (1.41 fold) in Z-VAD-FMK - treated cells than in untreated cells (11.8 fold) (Figure 1D).

TABLE 1. Apoptotic cells and fold changes in fluorescence intensity of MICA-S and MICA-NS C. parapsilosis strains treated with micafungin.

\begin{tabular}{|c|c|c|c|c|c|c|}
\hline \multirow{4}{*}{$\begin{array}{c}\text { Strains } \\
\text { C. parapsilosis }\end{array}$} & \multicolumn{6}{|c|}{ Apoptotic Cells } \\
\hline & \multicolumn{2}{|c|}{ Protoplast \% } & \multicolumn{4}{|c|}{ Fold change } \\
\hline & \multirow[t]{2}{*}{ Annexin V } & \multirow[t]{2}{*}{ PI } & \multicolumn{2}{|c|}{ ROS } & \multicolumn{2}{|c|}{$\Delta \Psi_{m}$} \\
\hline & & & $-N A C$ & +NAC & $-N A C$ & +NAC \\
\hline \multicolumn{7}{|l|}{ Isolate-1 (MICA-S) } \\
\hline Control & $5.0 \pm 0.01$ & - & - & - & - & - \\
\hline $0.25 \mathrm{mg} / \mathrm{L}$ & $24.0 \pm 2.0$ & - & $1.8 \pm 0.01$ & $1.5 \pm 1.00$ & $2.8 \pm 0.1$ & $1.9 \pm 0.01$ \\
\hline $0.5 \mathrm{mg} / \mathrm{L}$ & $52.0 \pm 3.0$ & $2.0 \pm 0.01$ & $2.4 \pm 0.2$ & $1.68 \pm 0.20$ & $3.8 \pm 0.4$ & $2.48 \pm 0.01$ \\
\hline $1.0 \mathrm{mg} / \mathrm{L}$ & $19.0 \pm 1.0$ & $9.0 \pm 1.0$ & $1.9 \pm 0.01$ & $1.61 \pm 0.21$ & $2.5 \pm 0.2$ & $1.8 \pm 0.01$ \\
\hline \multicolumn{7}{|l|}{ Isolate-6 (MICA-NS) } \\
\hline Control & $2.0 \pm 0.01$ & $1.0 \pm 0.01$ & - & - & - & - \\
\hline $0.5 \mathrm{mg} / \mathrm{L}$ & $7.0 \pm 1.0$ & - & $1.5 \pm 0.01$ & $1.0 \pm 0.02$ & $1.9 \pm 0.01$ & $1.4 \pm 0.10$ \\
\hline $1.0 \mathrm{mg} / \mathrm{L}$ & $30.0 \pm 2.0$ & - & $1.4 \pm 0.01$ & $1.3 \pm 0.01$ & $1.98 \pm 0.01$ & $0.89 \pm 0.01$ \\
\hline $2.0 \mathrm{mg} / \mathrm{L}$ & $11.0 \pm 1.0$ & $6.0 \pm 0.01$ & $1.6 \pm 0.01$ & $1.1 \pm 0.20$ & $2.0 \pm 0.01$ & $1.4 \pm 0.16$ \\
\hline
\end{tabular}

'-' Not detected ( $0 \%$ of cells showed particular apoptotic marker).

$\mathrm{PI}$, propidium iodide; ROS, reactive oxygen species; $\Delta \Psi_{\mathrm{m}}$, mitochondrial membrane potential; NAC, $N$-acetyl cysteine. 
A
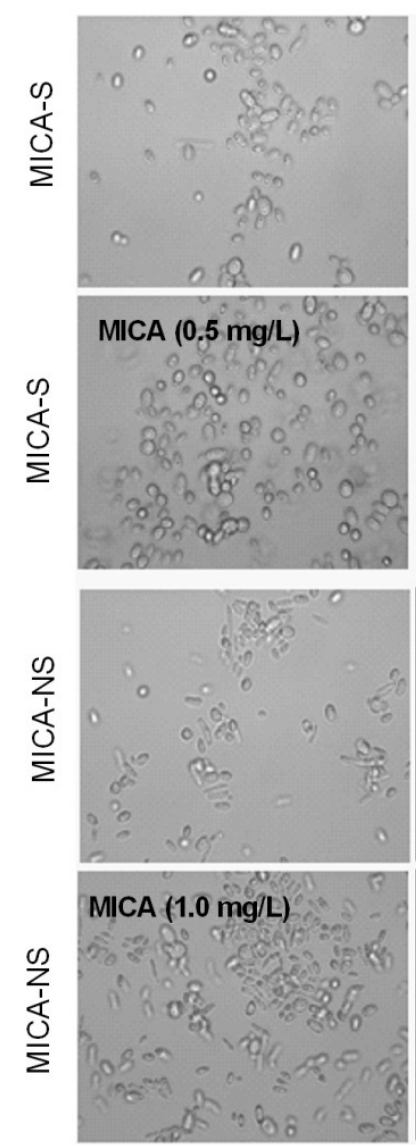

DIC
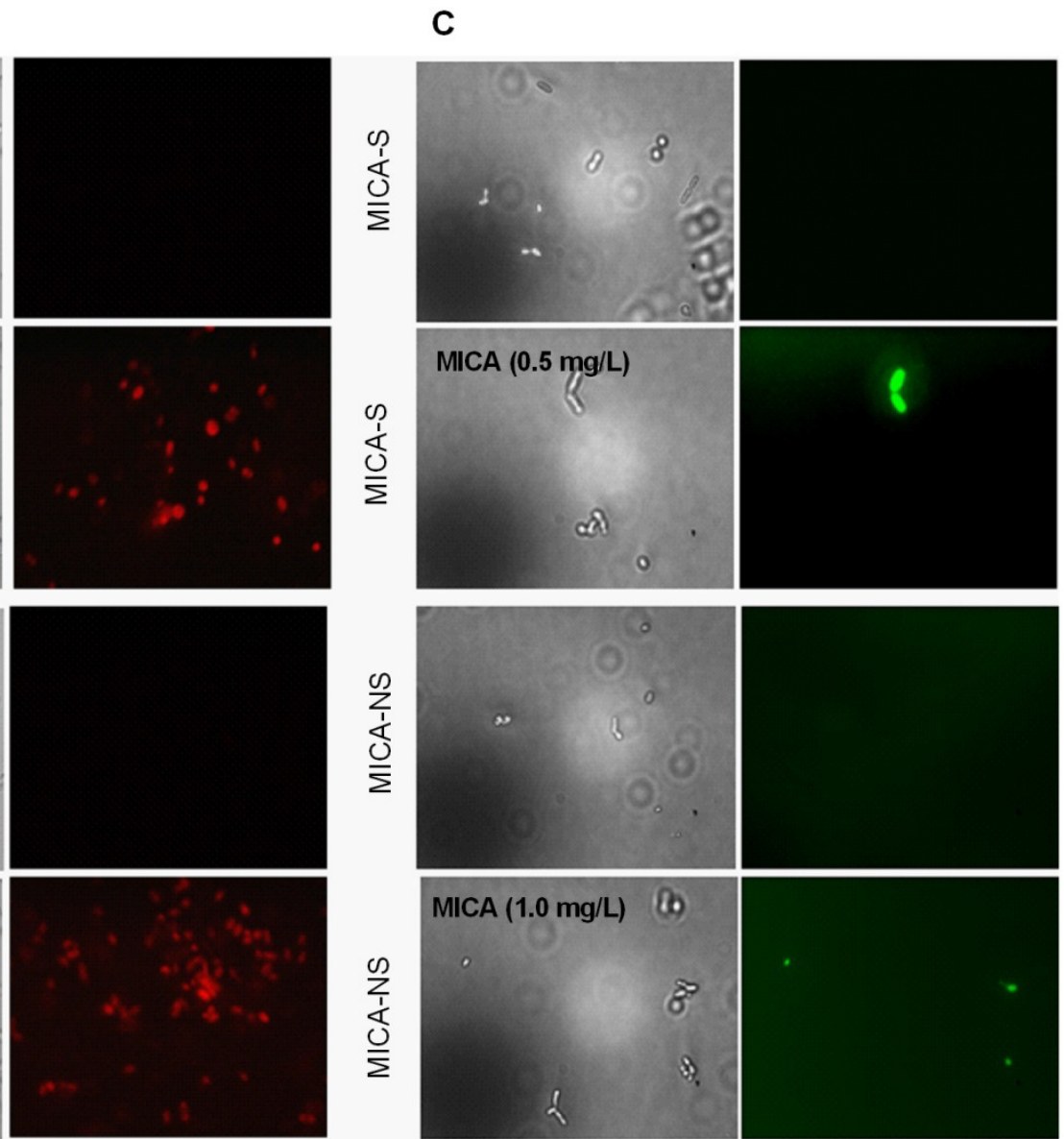

DHR-123

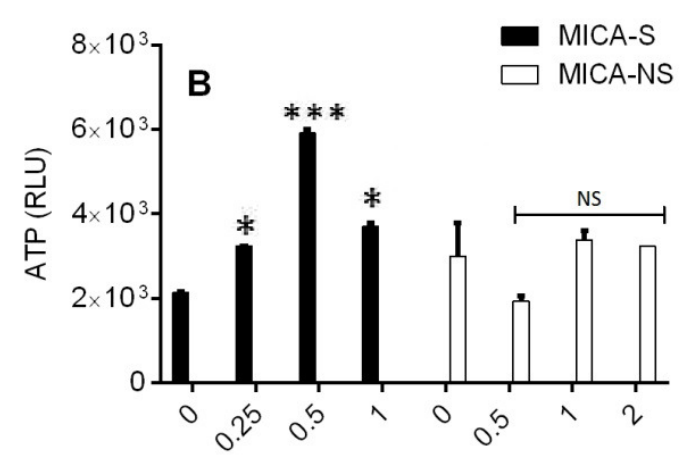

MICA Concentration (mg/L)

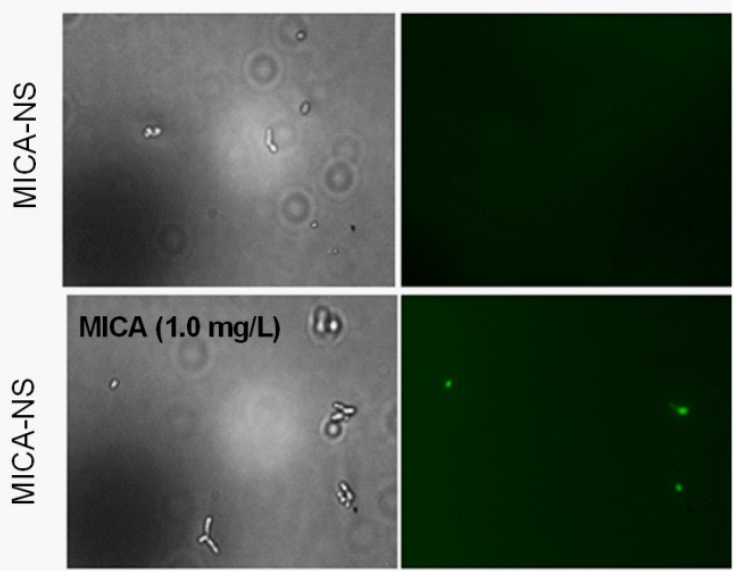

DIC

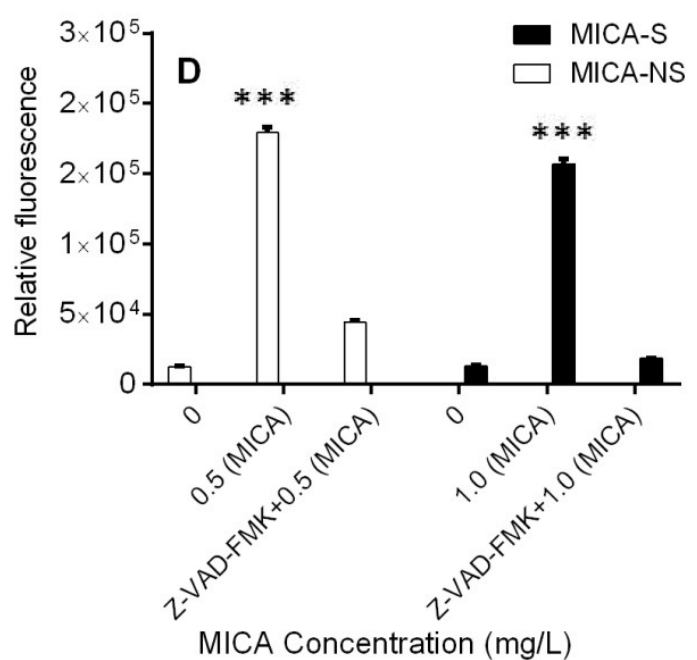

FIGURE 1: Intracellular ROS accumulation, ATP release and activation of caspase like activity in C. parapsilosis (MICA-S and MICA-NS isolates 1 and 6, respectively) cells treated with micafungin for $3 \mathbf{h}$ at $37^{\circ} \mathrm{C}$. (A) Fluorescence images of MICA-S and MICA-NS strains of C. parapsilosis treated with micafungin and stained for intracellular ROS with DHR-123. (B) ATP release assay indicating $C$. parapsilosis cell membrane disruption and plasma membrane leakage after micafungin treatment. (C) Fluorescent images of MICA-S and MICA-NS C. parapsilosis strains treated with micafungin and stained with caspase activity detection marker CaspACE FITC-VAD-FMK. (D) Relative fluorescence of $C$. parapsilosis MICA-S and MICA-NS cells treated with micafungin with or without caspase-1 inhibitor Z-VAD-FMK, and stained with caspase activity detection marker CaspACE FITC-VAD-FMK. DIC, Differential Interference Contrast; $C p, C$. parapsilosis; RLU, relative light units; *P < $0.05 ; * * * P<0.0001$; NS (non-significant), $\mathrm{P}>0.05$ (compared with untreated controls). 
Finally, to further elucidate the ROS role in apoptosis, we examined whether the ROS scavenger NAC reverses apoptosis in C. parapsilosis S and NS planktonic cells. At $37^{\circ} \mathrm{C}$, the levels of intracellular ROS were markedly decreased from 2.4 fold to 1.6 fold in susceptible cells and 1.6 to 1.0 fold in non-susceptible cells, after the addition of ROS scavenger $N$-acetyl-cysteine (NAC, $40 \mathrm{mM}$ ), compared to NAC unexposed cells (Table 1). Similar observation was evidenced in mitochondrial potential of $C$. parapsilosis $\mathrm{S}$ and NS planktonic cells treated with MICA in the presence of NAC (Table 1).

\section{DISCUSSION}

We found that MICA induced cellular apoptosis in both MICA-S and MICA-NS strains. After exposure to subinhibitory concentrations of MICA, PS was exposed on the outer surface of the plasma membrane, accompanied by an increase in intra-cellular ROS levels and depolarization of the mitochondrial membrane, which was marked by ATP and cytochrome $c$ release. Hao et al. [13] reported that caspofungin exerts its antifungal activity against $C$. albicans by apoptosis. In concordance with these reports, our results have described that dying $C$. parapsilosis cells exhibit markers of apoptosis following MICA exposure (0.25 - 2 $\mathrm{mg} / \mathrm{L}$ ). Our results show that apoptosis markers in C. parapsilosis were detectable following even sub-MIC MICA concentrations in both MICA-S and MICA-NS strains. In addition, a higher percentage of MICA-S C. parapsilosis cells underwent apoptosis compared to MICA-NS strains following MICA exposure. This phenomenon could be attributed to a more complex glucan matrix in the cell walls of the MICA-NS strains, which might account for MICA-NS strains resistance to antifungal drugs, as described previously [16].

Caspases, cysteine-aspartic acid proteases, when cleaved, induce apoptosis. In C. albicans, a putative caspase encoded by metacaspase (CaMCA1) has been shown to be involved in apoptosis $[12,13]$. In our study, we used CaspACE FITC-VAD-FMK, which detects activated caspases, to show that $C$. parapsilosis caspases are activated in response to MICA exposure. These data are consistent with the hypothesis that apoptosis of $C$. parapsilosis proceeds through metacaspase-dependent pathways, although further studies are needed to demonstrate how metacaspase activity contributes to this process.

In conclusion, MICA initiate apoptosis of $C$. parapsilosis cells at concentrations below the minimum inhibitory concentration in both MICA-S and MICA-NS strains, although more susceptible and non-susceptible $C$. parapsilosis strains will need to be tested to confirm generalization of our findings. The mechanism of the apoptotic pathways induced by MICA needs further clarification, as do the roles of apoptosis in determining the therapeutic efficacy of these echinocandins in vivo. Given the differences in the architecture of the death-regulating machineries of fungi and higher mammals [7], apoptotic pathways may represent important targets for novel antifungal drug development and should be further investigated as a new antifungal approach.

\section{MATERIALS AND METHODS}

\section{Echinocandins}

Pure MICA powder ( $5 \mathrm{mg} / \mathrm{mL}$ stock solution) was obtained from Astellas Pharma US, Inc. The stock dilutions were prepared in distilled water and stored at $-80^{\circ} \mathrm{C}$ until use.

\section{Isolates and growth conditions}

The $C$. parapsilosis isolates used in this study were from blood cultures of cancer patients with candidemia at The University of Texas MD Anderson Cancer Center, Houston, TX. Specifically, we used one MICA-S and one MICA-NS C. parapsilosis isolate. The isolates were grown on yeast peptone dextrose (YPD) agar plates overnight at $37^{\circ} \mathrm{C}$. The cells were then collected and washed twice in phosphate-buffered saline and counted using a hemocytometer (Hausser Scientific). Next, $10^{6}$ cells $/ \mathrm{mL}$ of each isolate were resuspended in liquid YPD and incubated at $37^{\circ} \mathrm{C}$ for $12 \mathrm{~h}$ until reaching mid-log phase, and recounted with a hemocytometer to achieve final testing inocula.

\section{Susceptibility testing}

We performed broth microdilution susceptibility testing according to the Clinical and Laboratory Standards Instituteapproved document M27-A3, in 96 well microtitration plates in RPMI 1640 medium (Corning Inc., New York, NY) containing serial two fold dilutions of micafungin and a final inoculum of $5 \times 10^{3}$ cells $/ \mathrm{mL}$ of each isolate. The minimum inhibitory concentration (MIC) of MICA for each isolate was determined visually $24 \mathrm{~h}$ after incubation at $37^{\circ} \mathrm{C}$ as the lowest concentration that resulted in a prominent decrease in turbidity (reduction of $>50 \%$ of growth) and the results were analyzed according to guidelines set for Candida susceptibility to echinocandins $[17,18]$.

Detection of apoptosis and necrosis with annexin $V$ and propidium iodide ( $\mathrm{PI}$ ) double staining of $\boldsymbol{C}$. parapsilosis cells The apoptosis marker phosphatidylserine (PS) is located on the inner leaflet of the lipid bilayer of the cytoplasmic membrane, and is translocated to the outer leaflet at the onset of apoptosis, where it can be identified by annexin $\mathrm{V}$ staining $[9$, $10,19]$. PI staining identifies necrotic cells, as it does not permeate cells in intact membranes. Therefore, staining patterns differentiate between live cells (Annexin V-/PI-), cells undergoing early apoptosis (Annexin $\mathrm{V}+/ \mathrm{PI}-$ ) and necrotic cells (Annexin $\mathrm{V}+/ \mathrm{PI}+)[19,20]$. Cells treated with micafungin $(0.25-2 \mathrm{mg} / \mathrm{L})$, were digested with a lysing enzyme mixture $(0.25 \mathrm{mg} / \mathrm{mL}$ of chitinase, $15 \mathrm{U}$ of lyticase, and $20 \mathrm{mg} / \mathrm{mL}$ lysing enzyme; Sigma-Aldrich) for $3 \mathrm{~h}$ at $30^{\circ} \mathrm{C}$. After digestion, cells were stained with the annexin $\mathrm{V}$ - fluorescein isothiocyanate (FITC) $(50 \mathrm{mg} / \mathrm{L}$, BD Pharmingen, USA) and $\mathrm{PI}(50 \mathrm{mg} / \mathrm{L})$ at room temperature (RT) for $15 \mathrm{~min}$ and then observed under a Nikon Microphot SA fluorescence microscope to assess the externalization of the apoptosis marker PS as previously described $[9,10]$.

\section{Detection of intracellular ROS in C. parapsilosis cells}

Intracellular ROS levels in C. parapsilosis cells were measured as previously described $[9,10]$. C. parapsilosis cells were treated with MICA $(0.25-2 \mathrm{mg} / \mathrm{L})$ for $3 \mathrm{~h}$ at $37^{\circ} \mathrm{C}$. Cells were then spiked with dihydrorhodamine (DHR)-123 (5 mg/L). After incubation for $2 \mathrm{~h}$ at RT, cells were harvested after centrifugation at $13,000 \times g$ for 5 min and observed with a Nikon Microphot SA fluorescence microscope (excitation, $488 \mathrm{~nm}$; emission, $520 \mathrm{~nm}$ ). For quantitative assays, fluorescence intensity 
values were recorded using a POLARstar Galaxy microplate reader (excitation, $490 \mathrm{~nm}$; emission, $590 \mathrm{~nm}$; BMG LABTECH, Offenburg, Germany). The same experiment was conducted in the presence of NAC at a concentration of $40 \mathrm{mM}$.

\section{Mitochondrial membrane potential $\left(\Delta \Psi_{m}\right)$ measurements in C. parapsilosis cells}

Mitochondrial membrane depolarization was assessed by staining with rhodamine (Rh)-123, a fluorescent dye that is distributed in the mitochondrial matrix as previously described $[9,10]$. Briefly, the cells were exposed to micafungin $(0.25-2$ $\mathrm{mg} / \mathrm{L}$ ) for $3 \mathrm{~h}$ at $37^{\circ} \mathrm{C}$ and harvested via centrifugation, washed twice, then resuspended in phosphate-buffered saline. Rh-123 was added to the final concentration of $10 \mu \mathrm{M}$ and was incubated for $30 \mathrm{~min}$ in the dark at RT. Fluorescence intensity was recorded as described above. The same experiment was conducted in the presence of NAC at a concentration of $40 \mathrm{mM}$.

\section{Adenosine triphosphate (ATP) release assay in C. parapsilosis cells}

We assessed the severity of MICA-induced mitochondrial and plasma membrane damage by the amount of cellular ATP released into the medium as described by Ben-Ami et al. [21]. The $C$. parapsilosis cells were then counted with a hemocytometer (Hausser Scientific), and suspended in RPMI 1640 medium at $10^{6}$ cells $/ \mathrm{mL}$. After $12 \mathrm{~h}$ at $37^{\circ} \mathrm{C}$, the medium was removed by centrifugation at $13,000 \times \mathrm{g}$ for five min and cells were re-suspended in MICA-containing $(0.25-2 \mathrm{mg} / \mathrm{L})$ or drug-free RPMI 1640 medium. After $3 \mathrm{~h}$ of incubation, the cells were removed by centrifugation as described above and the ATP released in the supernatants was assayed by using the CellTiter-Glo luminescent kit (Promega). Data were recorded with a microplate luminometer (SpectraMax M5; Molecular Devices).

\section{Detection of metacaspase activity in C. parapsilosis cells} Activation of metacaspases was detected with the CaspACE FITC-VAD-FMK in situ Marker (Promega) $[9,10]$. The cells were pretreated with MIC $(0.5-1 \mathrm{mg} / \mathrm{L})$ for $3 \mathrm{~h}$ at $37^{\circ} \mathrm{C}$. Cells were harvested, washed in phosphate-buffered saline, and then resuspended in $10 \mu \mathrm{M}$ CaspACE FITC-VAD-FMK solution. After 2 $h$ of incubation at RT, cells were washed twice and resuspended in phosphate-buffered saline. Samples were

\section{REFERENCES}

1. Phillips AJ, Sudbery I, and Ramsdale M (2003). Apoptosis induced by environmental stresses and amphotericin B in Candida albicans. Proc Natl Acad Sci U. S. A. 100:14327-14332.

2. Ostrosky-Zeichner L, Casadevall A, Galgiani JN, Odds FC and Rex $\mathrm{JH}$ (2010). An insight into the antifungal pipeline: selected new molecules and beyond. Nat Rev Drug Discov 9:719-727.

3. Nguyen LN, Cesar GV, Le GTT, Silver DL, Nmrichter L, and Nosanchuk JD (2012). Inhibition of Candida parapsilosis fatty acid synthase (Fas2) induces mitochondrial cell death in serum. PLoS Pathog 8:e1002879.

4. Walraven CJ, Lee SA (2013). Antifungal lock therapy. Antimicrob Agents Chemother 57: 1-8. mounted and viewed in a Nikon Microphot SA fluorescence microscope (excitation, $488 \mathrm{~nm}$; emission, $520 \mathrm{~nm}$ ).

Inhibition of apoptosis was performed by incubating $C$. parapsilosis planktonic cells with MICA, in the presence or absence of the caspase-1 inhibitor Z-VAD-FMK (Sigma) and the antioxidant $\mathrm{N}$-acetyl-cysteine (NAC) at final concentrations of $40 \mu \mathrm{M}$ and $40 \mathrm{mM}$, respectively. After incubation for $3 \mathrm{~h}$, cells were analysed for ROS accumulation, mitochondrial potential and metacaspase activity.

\section{Statistical analysis}

For all assays, three independent experiments were performed on different days in triplicate. Multiple treatment groups were compared using Kruskall-Wallis test and post-hoc paired comparisons were compared using Dunnett's tests. Calculations were made with InStat (GraphPad Software). All results are expressed as means \pm standard deviations. Twotailed $P$ values of less than 0.05 were considered statistically significant.

\section{ACKNOWLEDGMENTS}

D.P.K. acknowledges the Frances King Black Endowed Professorship for Cancer Research. This research was supported in part by a Research Grant from Astellas Pharma Inc.

\section{CONFLICT OF INTEREST}

D.P.K. has received research support and honoraria from Pfizer; Astellas Pharma US, Inc.; Merck \& Co., Inc.; T2 Biosystems. F.S. and R.E.L. have no conflicts of interest.

\section{COPYRIGHT}

(C) 2015 Shirazi et al. This is an open-access article released under the terms of the Creative Commons Attribution (CC BY) license, which allows the unrestricted use, distribution, and reproduction in any medium, provided the original author and source are acknowledged.

Please cite this article as: Fazal Shirazi, Russel E. Lewis, Dimitrios P. Kontoyiannis (2015). Micafungin induced apoptosis in Candida parapsilosis independent of its susceptibility to micafungin. Microbial Cell 2(11): 445-450. doi: 10.15698/mic2015.11.236
5. Andes DR, Safdar N, Baddley JW, Playford G, Reboli AC, Rex JH, Sobel JD, Pappas PG, and Kullberg BJ (2012). Impact of treatment strategy on outcomes in patients with candidemia and other forms of invasive candidiasis: a patient-level quantitative review of randomized trials. Clin Infect Dis 54:1110-1122.

6. Georgopapadakou NH and Tkacz JS (1995). The fungal cell wall as a drug target. Trends Microbiol 3:98-104.

7. Almeida B, Silva A, Mesquita A, Sampaio-Marques B, Rodrigues F, and Ludovico P (2008). Drug-induced apoptosis in yeast. Biochimica et Biophysica Acta -Mol Cell Res 1783:1436-1448.

8. Ramsdale M (2008). Programmed cell death in pathogenic fungi. Biochim Biophys Acta 1783:1369-1380. 
9. Shirazi F and Kontoyiannis DP (2013). Mitochondrial respiratory pathways inhibition in Rhizopus oryzae potentiates activity of posaconazole and itraconazole via apoptosis. PLoS One 8:e63393.

10. Shirazi F, Pontikos MA, Walsh TJ, Albert N, Lewis RE, and Kontoyiannis DP (2013). Hyperthermia sensitizes Rhizopus oryzae to posaconazole and itraconazole action through apoptosis. Antimicrob Agents Chemother 57:4360-4368.

11. Munoz AJ, Wanichthanarak K, Meza E and Petranovic D (2012).Systems biology of yeast cell death. FEMS Yeast Res 12:249265

12. Chin C, Donaghey F, Helming K, McCarthy M, Rogers S, and Austriaco N (2014). Deletion of AIF1 but not of YCA1/MCA1 protects Sac charomyces cerevisiae and Candida albicans cells from caspofungininduced programmed cell death. Microbial Cell 1:58-63.

13. Hao B, Cheng S, Clancy CJ, and Nguyen MH (2013). Caspofungin kills Candida albicans by causing both cellular apoptosis and necrosis. Antimicrob Agents Chemother 57:326-332.

14. Al-Dhaheri RS and Douglas $\amalg$ (2010). Apoptosis in Candida biofilms exposed to amphotericin B. J Med Microbiol 59:149-157.

15. Hamann A, Brust D, and Osiewacz HD (2008). Apoptosis pathways in fungal growth, development and ageing. Trends Microbiol 16:276283.

16. Taff HT, Nett JE, Zarnowski R, Ross KM, Sanchez H, Cain MT, Hamaker J, Mitchell AP, and Andes DR (2012). A Candida biofilminduced pathway for matrix glucan delivery: implications for drug resistance. PLOS Pathog 8:e1002848.
17. Clinical and Laboratory Standards Institute (2008). Reference method for broth dilution antifungal susceptibility testing of yeast. $3^{\text {rd }}$ ed. M27-A3. Clinical and Laboratory Standards Institute document M27-A2. Clinical and Laboratory Standards Institute, Wayne, PA.

18. Espinel-Ingroff $A 1$, Arendrup MC, Pfaller MA, Bonfietti LX, Bustamante $B$, Canton E, Chryssanthou E, Cuenca-Estrella M, Dannaoui $E$, Fothergill A, Fuller J, Gaustad P, Gonzalez GM, Guarro J, Lass-Flörl C, Lockhart SR, Meis JF, Moore CB, Ostrosky-Zeichner L, Pelaez T, Pukinskas SR, St-Germain G, Szeszs MW, and Turnidge J (2013). Interlaboratory variability of Caspofungin MICs for Candida spp. Using CLSI and EUCAST methods: should the clinical laboratory be testing this agent? Antimicrob Agents Chemother 57:5836-5842.

19. Ben-Ami R, Lewis RE, Tarrand J, Leventakos K, and Kontoyiannis DP (2010). Antifungal activity of colistin against Mucorales species in vitro and in a murine model of Rhizopus oryzae pulmonary infection. Antimicrob Agents Chemother 54:484-490.

20. Madeo F, Fröhlich E, Ligr M, Grey M, Sigrist SJ, Wolf DH, and Fröhlich KU (1999). Oxygen stress: a regulator of apoptosis in yeast. J Cell Biol 145:757-767.

21. Cho J and Lee DG (2011). Oxidative stress by antimicrobial peptide pleurocidin triggers apoptosis in Candida albicans. Biochimie 93:1873-1879. 